\title{
Towards a sustainable and equitable blue economy
}

\section{The global rush to develop the 'blue economy' risks harming both the marine environment and human wellbeing. Proactive, systematic and bold policies and actions are urgently required to chart an environmentally sustainable and socially equitable course for the blue economy.}

Concerns about the state of the world's oceans are widespread ${ }^{1,2}$. At the same time, interest in their untapped economic potential is escalating. The Organization for Economic Co-operation and Development (OECD) projects that the contribution of the ocean to global GDP could double from US $\$ 1.5$ trillion in 2010 to US $\$ 3$ trillion by $2030^{3}$. Ocean sectors, including fisheries, aquaculture, marine tourism, bio-prospecting, seabed mining, oil and gas, renewable energy, and shipping, are heralded by numerous actors and nations as lucrative frontiers for investment. The 'blue economy' - a term that encapsulates international interest in the growth of ocean-based economic development - has been a central theme in numerous recent global ocean policy conferences ${ }^{4,5}$.

Many developing coastal countries and small-island developing states (SIDS) also see promise in ocean-based industries, and view the oceans as a source of wealth and focus for development ${ }^{6,7}$. Indeed, SIDS were among the first to advocate for attention to the blue economy, which, in their vision, features social equity and environmental sustainability as core tenets ${ }^{7,8}$ (Figure 1). However, there is a real risk that these tenets are being sidelined in policy and practice in the push for aggregate economic growth through ocean development.

Figure 1 - The blue economy must feature environmental sustainability and social equity as core tenets

\section{Sustainability and equity in the blue economy}

Healthy oceans are fundamental to prosperity and human wellbeing. Attention to ocean sustainability has grown steadily since the Earth Summit in 1992 and accelerated with the 2015 adoption of Sustainable Development Goal 14: Life Below Water. However, ocean-based industries and human activities are having substantial negative impacts on marine habitats, species and productivity ${ }^{1,2,9}$. Further exploitation and new extractive industries may simply place further burdens on the already stressed marine environment. New forms of development, such as seabed mining, come with relatively unknown environmental risks. Furthermore, the cumulative impacts of existing and new oceans uses, coupled with pressures associated with climate change and land-based sources of pollution, remain poorly understood ${ }^{10}$. Yet, policy frameworks and environmental assessment processes sufficient to understand and manage the environmental risks of the blue economy are nascent and, in many places, do not exist.

Our ability to understand and address the distribution of social benefits and harms from the blue economy is equally inadequate. Potential benefits include revitalization of coastal economies, provision of alternative livelihoods, and improved food security and well-being in coastal communities and island nations ${ }^{3,6,7}$. New economic opportunities may also enable SIDS and coastal states to re-assert sovereign control and regain access to marine resources. However, the assumption of a "trickle-down" blue economy is problematic. Unregulated economic growth can produce economic winners and losers, generate limited local benefits due to elite capture, create damaging social and cultural impacts, expose marginalized groups to pollution, and displace local populations. Mounting evidence from the global 
fishing industry demonstrates how unchecked development can lead to human rights abuses, including enslavement, and erosion of local access to fisheries and food security ${ }^{11}$. International social movements claim that 'ocean grabbing' is occurring as ocean spaces and resources are enclosed and privatized for blue growth ${ }^{12}$. Similar issues have been reported in other maritime sectors (e.g., aquaculture, oil), such that discussions of social equity and 'blue justice' are emerging at global meetings. At the 2018 Sustainable Blue Economy conference in Kenya, for example, specific concerns relating to small-scale fisheries (SSF), Indigenous peoples, women and youth featured prominently. However, the rhetoric of equity, inclusion and benefit sharing appears to be outpacing both policy creation and the implementation of best practices.

\section{Ocean governance and the blue economy}

Addressing sustainability and equity issues demands attention to governance. However, ocean governance is subject to a high degree of complexity and often lacks coherence and coordination ${ }^{4}$. International, regional, and national governance frameworks establish jurisdiction and authority over marine resources and areas of the ocean. The United Nations Convention on the Law of the Sea (UNCLOS) is the fundamental international legal and governance framework that allocates sovereign exclusive economic zones (EEZs) and identifies what remains as common global property (i.e., 'the high seas'). Under UNCLOS, global institutions - including the International Tribunal for the Law of the Sea, the International Seabed Authority, and the Commission on the Limits of the Continental Shelf - were established to deliberate on ocean issues and marine resources of interest to blue economy advocates. Within EEZs, nation states have jurisdiction and hold authority for fisheries management, biodiversity conservation, and the allocation of rights for military, shipping or development (e.g., aquaculture, oil, mining) purposes. Regional governance mechanisms - such as Regional Fisheries Management Organizations, Regional Seas Programmes, and Large-Marine Ecosystem Programmes - enable states to collaborate on multi-lateral sustainability challenges. However, across sectors and spatial scales, significant regulatory and institutional gaps still exist.

Furthermore, ocean resources and spaces are often shared and accessed by numerous local users and groups - including coastal communities, small-scale fishermen and fisherwomen, and Indigenous peoples - who have a right to participate in decisions regarding how property rights, resources and benefits from the blue economy are allocated ${ }^{13}$. Local citizens and civil society organizations are likely to express opposition when they are marginalized from decision-making or are concerned about the potential environmental damages or social harms of new developments. State laws and legitimacy will be tested when Indigenous peoples or SSF assert their territorial rights to coastal and ocean spaces and/or demand free, prior, and informed consent for new and expanded marine developments ${ }^{14}$. Geopolitical tensions may increase as neighboring states seek to lay claim to valuable ocean spaces and resources, countries will more stridently police and enforce their EEZs, and, in the case of developing coastal states and SIDS, demand their fair share of benefits from migratory fish stocks (e.g., tuna), seabed minerals, and marine bio-resources ${ }^{15}$.

\section{Charting a course for the blue economy}

Proactive, systematic and bold policies and actions are needed as ocean development proliferates within EEZs and in areas beyond national jurisdiction (ABNJ). Here, we identify five priorities to 'chart a course' for environmentally sustainable and socially equitable blue growth.

First, environmental sustainability and social equity must be prioritized in international negotiations and instruments relating to the oceans and ocean development. A number of global agreements - 
including the Convention on Biological Diversity, the UN Sustainable Development Goals, the UN Declaration of Human Rights, and the UN Declaration on the Rights of Indigenous Peoples -contain commitments relating to sustainability and equity. UNCLOS and numerous other ocean guidelines and conventions also touch on these issues. Yet neither an obvious coordinating body nor a comprehensive set of blue economy guidelines currently exists. Thus, we recommend that the UN establish or designate a commission or agency within the Economic and Social Council system to be responsible for synthesizing best practices and developing international guidelines for the implementation, monitoring and management of blue economy activities. Developing international guidelines would provide a foundation for international deliberations and multi-lateral discussions, as well as guidance for national policies and corporate activities. Such an initiative would require resources, time and broad support. Several pre-existing initiatives show momentum and provide building blocks including the FAO Voluntary Guidelines for Securing Sustainable Small-Scale Fisheries, The Commonwealth Blue Charter, and The European Commission's Blue Growth Strategy.

Second, comprehensive legislation and effective regulatory agencies are necessary pre-conditions for sustainable blue economy development within national jurisdictions. National governments should thus strategize and focus their efforts on: addressing regulatory and institutional gaps that exist within current legal and governance frameworks; ensuring coherent policy coverage across different agencies and sectors (e.g., fishing, aquaculture, tourism, renewable energy, seabed mining, oil and gas, shipping); enabling integrated, inter-sectoral and science-based planning and management; harmonizing across jurisdictions and with international institutions; and, providing adequate financing to support management capacity and to ensure accountability. While many countries (e.g., Seychelles, South Africa, Grenada, Norway) are convening diverse groups of experts and stakeholders to tackle challenges associated with the emerging blue economy, other national governments must act quickly.

Third, national governments also ought to develop guidelines that require equitable treatment of local populations and sharing of any wealth generated through blue growth. Insights may be gleaned from international agreements, existing corporate codes of conduct and principles of social responsibility ${ }^{11}$. Key considerations include: recognizing and protecting the tenure and access rights of coastal and Indigenous populations to fisheries and areas of the ocean; ensuring that labor and human rights are respected; establishing mechanisms to improve social and economic benefits (e.g., impactbenefit agreements, hiring and procurement procedures, capacity building) for local communities; and, creating pathways to increase local ownership (e.g., technology transfer, credit schemes, connections to markets). These actions will also help the private sector to create and maintain social license to operate in coastal and ocean spaces.

Fourth, inclusive governance of the blue economy at all scales is required to realize social equity and sustainability. Contemporary environmental governance consists of decision-making structures and processes that catalyze participation among governments, the private sector and civil society ${ }^{16}$. Civil society (including scientists, media, NGOs, and marginalized groups) must be represented in decisionmaking processes focused on how the ocean will be developed and by whom, how and to whom benefits will be distributed, how harms will be minimized, and who will bear responsibility for environmental and social outcomes. At the international scale, SIDS and coastal developing nations, indigenous groups and SSF organizations, and NGOs are actively advocating for their own visions for the blue economy. Yet, these oft marginalized groups and less economic ideas are sometimes sidelined in global oceans governance ${ }^{5,13}$. One strategy that smaller delegations of nations and civil society organizations can use to overcome this is to strategize and work in blocs through international and multilateral processes to assert shared objectives. At the national scale, inclusive governance of the blue economy may require legal obligations that necessitate participation, adequate funding mechanisms for meaningful 
engagement, government mandates that ensure information transparency, and well-designed decisionmaking processes that ensure all voices are heard and incorporated into decisions. For example, marine spatial planning (MSP) plays a critical role in helping to overcome the sector-by-sector approach found in ocean governance. However, to be effective and equitable, MSP must be undertaken with significant attention to representation, power-dynamics and appreciation for how new boundaries, rights and activities can impact tenure, rights, livelihoods and food security of local communities.

Figure 2 - A model for inclusive governance of the blue economy

Finally, at all scales, insights from and investments in interdisciplinary ocean science will be needed to inform international negotiations, design ocean policy, shape blue economy initiatives, and monitor social and environmental impacts and outcomes. The upcoming UN Decade of Ocean Science for Sustainable Development (2021-2030) offers an important opportunity to identify how natural and social science can be employed and mobilized to enable the realization of a sustainable and equitable blue economy.

\section{A window of opportunity for transformation}

Producing a sustainable and equitable blue economy rests on the proactive and rapid design and implementation of systematic policies and bold actions, based on interdisciplinary ocean science and made through inclusive governance processes. There are several upcoming policy windows to chart the course of the blue economy. The Norwegian Prime Minister has convened a "High-level panel for a sustainable ocean economy" made up of 14 sitting heads of state and governments to create a roadmap for sustainable ocean development. Global policy-makers will assemble at the sixth annual Our Ocean Conference hosted by Norway in October 2019 and the second UN Ocean Conference in Portugal in June 2020. Yet, these international policy initiatives could simply mean "business-as-usual” for the blue economy, by which we mean unsustainable practices and elite capture of economic benefits, or they could transform how we govern and develop the oceans going forward. Getting it wrong will have dire consequences for the ocean and people who depend on it.

\section{References}

1. Nash, K. L. et al. Planetary boundaries for a blue planet. Nat. Ecol. Evol. 1, 1625 (2017).

2. Halpern, B. S. et al. Spatial and temporal changes in cumulative human impacts on the world's ocean. Nat. Commun. 6, 7615 (2015).

3. OECD. The Ocean Economy in 2030. (2016).

4. Campbell, L. M. et al. Global Oceans Governance: New and Emerging Issues. Annu. Rev. Environ. Resour. 41, 517-543 (2016). 
5. Silver, J. J., Gray, N. J., Campbell, L. M., Fairbanks, L. W. \& Gruby, R. L. Blue Economy and Competing Discourses in International Oceans Governance. J. Environ. Dev. 24, 135-160 (2015).

6. World Bank \& United Nations. The Potential of the Blue Economy: Increasing Long-Term Benefits of the Sustainable Use of Marine Resources for Small Island Developing States and Coastal Least Developed Countries. (World Bank, 2017).

7. Michel, J. A. Rethinking the Oceans: Towards the Blue Economy. (Paragon House, 2017).

8. UN. Blue Economy Concept Paper: Rio+20 United Nations Conference on Sustainable Development. (2012).

9. Golden, J. S. et al. Making sure the blue economy is green. Nat. Ecol. Evol. 1, 0017 (2017).

10. Klinger, D. H., Maria Eikeset, A., Davíðsdóttir, B., Winter, A.-M. \& Watson, J. R. The mechanics of blue growth: Management of oceanic natural resource use with multiple, interacting sectors. Mar. Policy 87, 356-362 (2018).

11. Kittinger, J. N. et al. Committing to socially responsible seafood. Science 356, 912-913 (2017).

12. Bennett, N. J., Govan, H. \& Satterfield, T. Ocean grabbing. Mar. Policy 57, 61-68 (2015).

13. Cohen, P. J. et al. Securing a Just Space for Small-Scale Fisheries in the Blue Economy. Front. Mar. Sci. 6, UNSP 171 (2019).

14. Kerr, S., Colton, J., Johnson, K. \& Wright, G. Rights and ownership in sea country: implications of marine renewable energy for indigenous and local communities. Mar. Policy 52, 108-115 (2015).

15. Suárez-de Vivero, J. L. \& Rodríguez Mateos, J. C. Forecasting geopolitical risks: Oceans as source of instability. Mar. Policy 75, 19-28 (2017).

16. Lemos, M. C. \& Agrawal, A. Environmental Governance. Annu. Rev. Environ. Resour. 31, 297-325 (2006). 